\title{
The WHO must reform for its own health
}

\author{
Tikki Pang \& Laurie Garrett
}

\begin{abstract}
The World Health Organization (WHO) is facing an unprecedented crisis that threatens its position as the premier international health agency. To ensure its leading role, it must rethink its internal governance and revamp its financing mechanisms.
\end{abstract}
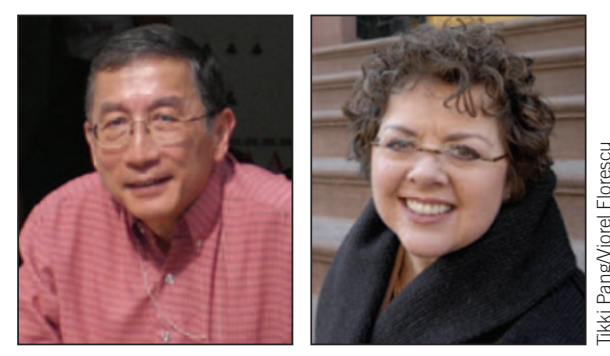

The World Health Organization was born in the bifurcated Cold War world in 1948, and every aspect of its charter, mission and organizational structure was molded by diplomatic tensions between NATO and the USSR. However, with the collapse of the Soviet Union and the rise of the new emerging market superpowers, the WHO finds itself trying to straddle a global dynamic for which it was not designed.

Indeed, the WHO now finds itself marginalized in a crowded global health landscape characterized by poor coordination among multiple players. It is no longer the only major actor. At the same time, it faces an internal crisis, with major budget shortfalls and staff layoffs that have resulted in the organization embarking on the most radical reforms in its 64 -year history ${ }^{1}$. But the changes do not go far enough. A recent dialogue on WHO reform that we participated in, held by the Council on Foreign Relations in New York in February, identified several key challenges that should be addressed by the agency.

First and foremost, the WHO should refocus on its original aim of being primarily a 'knowledge broker' that gives advice and information about best practices but stops short of directly implementing programs ${ }^{2}$. It should convene negotiations resulting in internationally binding legal agreements and monitor their implementation. Some of its most successful achievements-such as the Framework Convention on Tobacco Control, the International Health Regulations and the International Classification of Diseasesfall into this category.

The means by which such agreements are reached has changed, and the organization needs to adapt. In 1948, the WHO acted as a knowledge-and-standards broker between states, working almost exclusively with ministries of health and government leaders. In the twenty-first century, however, the WHO's credibility and relevance depend on its ability to exert a normative influence through the Internet, informing the global citizenry about all aspects of healthfrom relevant treaties to drug safety to disease outbreaks. Currently, the organization's website, http://www.who.int, is nearly impossible to navigate, akin to a well-stocked library with no catalog system. It needs an overhaul to be useful to the global citizenry.

The WHO not only needs to better communicate and coordinate with its global partners; it also needs to make improvements within, starting with its internal governance. The organization must enhance the relationship between its Geneva headquarters and its powerful regional offices. Guidance from Geneva is sometimes ignored, even contradicted, by the regional directors and their offices. Although the WHO was born with a clear top-down leadership structure, it has morphed over the decades into something closer to a partnership: Geneva 'suggests' policies that its regional partners may accept, ignore or amend. It is often difficult to tell whether the tail is wagging the dog. For example, the Pan American Health Organization, which is one of the regional offices of the WHO, may choose to design and implement a Chagas disease eradication strategy having sought little or no input from Geneva. To avoid tensions, the organization should more clearly apportion 'core' versus 'support' roles played by the various parties ${ }^{3}$.

The internal changes must also involve improved finances. In 1990, the agency was by far the largest player on the global health field, with an annual budget of nearly $\$ 1.2$ billion; the next biggest budget at the time was that of US government global health programs, which totaled $\$ 850$ million. By 2010, the WHO's budget, after years of increases, fell back to that 1990 level, making it the fourth largest spender in the global health landscape, behind the nowmammoth $\$ 7.5$ billion US program, the $\$ 3$ billion Global Fund to Fight AIDS, Tuberculosis and Malaria and the $\$ 2.2$ billion collective pile of smaller nongovernmental organizations. This year, the WHO seems to be falling further behind in the hierarchy, trailing the GAVI Alliance and the Bill \& Melinda Gates Foundation.

Until recently, the WHO garnered more than $80 \%$ of its budget in the form of voluntary donations, largely given by the wealthiest countries for earmarked programs. The agency's core support is derived from proportional levies on member nations, which have remained unchanged for years despite the rising costs of WHO operations. Moreover, the WHO's revenues are received in US dollars, but its Geneva operational and payroll costs must be met in Swiss francs. Because the WHO has not practiced currency hedging, a 32\% increase in the value of the franc against the dollar, as occurred in 2011, cannot be accommodated without severe institutional fiscal pain.

In addition to practicing currency hedging, the WHO must identify a range of financing innovations with a goal of increasing institutional resilience. Such financing mechanisms may include, for example, the establishment of an endowment fund, a multiyear financing framework, or the use of a Robin Hood tax, which reaps financing from miniscule taxation of very large currency transactions. Both of these options were highlighted by a 5 April report from a consultative expert working group convened by the WHO. And, like any multibillion-dollar company, the WHO should have an effective 'marketing' strategy built around rigorous, external evaluations that demonstrate the value of its activities.

The world needs an aggressive and scientifically solid health leader. Governance and the setting of normative standards cannot be accomplished with a slew of loosely connected health initiatives, nongovernmental organizations and bilateral programs. The only entity with a charter, a legislative body and a mandate to fill that role is the WHO, and it must do so decisively.

Tikki Pang is a visiting professor at the National University of Singapore and former director of Research Policy \& Cooperation at the World Health Organization in Geneva, Switzerland.

Laurie Garrett is a senior fellow for global health at the Council on Foreign Relations in New York, NY, USA.

1. World Health Organization. <http://apps.who.int/gb/ebwha/pdf_files/EB130/ B130_5-en.pdf> (2011).

2. Chow, J.C. Is the WHO becoming irrelevant? Foreign Policy (8 December 2010).

3. Jamison, D.T. et al. Lancet 351, 514-517 (1998). 